\title{
Saklıgöl (Denizli) Population Size of Pelophylax bedriagae (Levantine frog) Species
}

\author{
Hatice YANGIN, Didem ÇAPAR, Ömer DİLBE, Eyup BAŞKALE* \\ Pamukkale University, Faculty of Science E Arts, Department of Biology, 20017 Denizli, Turkey
}

\begin{abstract}
Received: 01.12 .2017
Accepted: 26.12 .2017

Available online: 28.12 .2017

Published: 29.12.2017

Abstract: In this study, information is given about $P$. bedriagae's population size and the changes that threaten the future of its population in the habitat that inhabits in Sakligöl of Yukarıdağdere, Honaz. In this context, the population size of $P$. bedriagae was estimated as $544(\mathrm{CI}=95 \%$; 353-899) individuals. The average recapture probability and the average survival rate were calculated as 0.62 and 0.32 respectively. Generally, populations of wild organisms are under the risk due to anthropogenic habitat destruction. Frogs that are extremely sensitive against changes that may occur in the habitat are good indicators in the analysis of many biological problems and the identification of problems that may occur in wetlands.

Keywords: Capture-mark-recapture method, population size, survival rate

\section{Saklıgöl'de (Denizli) Pelophylax bedriagae (Levanten kurbağa) Türünün Populasyon Büyüklüğü}

Özet: Bu çalışmada Saklıgöl'de (Yukarıdağdere Köyü, Honaz, Denizli) yaşayan P. bedriagaénin populasyon büyüklüğü ve populasyonun geleceğini tehdit eden etkenler hakkında bilgi verilmiştir. Bu kapsamda, $P$. bedriagae türünün Saklıgöl populasyonunun büyüklüğü 544 birey (\% 95'lik Güven Aralığı= 353-899) olarak hesaplanmıştır. Yapılan bu çalışmada ortalama yakalanma olasılığı 0,62 ve ortalama hayatta kalma oranı 0,32 olarak hesaplanmıştır. İnsan kaynaklı habitat tahribatları nedeniyle doğal populasyonlar genellikle risk altına girmektedir. Habitatta meydana gelebilecek değişikliklere karşı son derece hassas olan kurbağalar, sulak alanlarda meydana gelebilecek sorunların belirlenmesinde ve birçok biyolojik problemin çözümlenmesinde iyi bir indikatör canlılardır.
\end{abstract}

Anahtar kelimeler: Yakala-markala-tekrar yakala yöntemi, populasyon büyüklüğü, hayatta kalma oranı

\section{Giriş}

Dünyada Aralık 2017 verilerine göre yaklaşık 7450 amfibi türü yaşamakta olup bunların yaklaşık olarak 7778 türü Anura takımına aittir (AmphibiaWeb 2017). Türkiye'de göl, dere, çay, nehir gibi iç sularda ve bazı nemli ortamlarda yaşayan yaklaşık 30'u aşkın amfibi türü bulunmaktadır (Baran ve Atatür 1998; Budak ve Göçmen 2005, IUCN 2017, Sarikaya ve ark. 2017). Bu türlerden biri olan Pelophylax bedriagae diğer adiyla Levanten Ova Kurbağası, bir Güney Avrupa türüdür ve Ranidae familyasına aittir. Bu türün sırt tarafında koyu lekeler bulunur ve vücudu renkli kahverengi yeşildir. Erkek bireylerin ağzının hemen arkasında timpanal zarın altında, gri renkli dış ses kesesi bulunur. P. bedriagae türünde sırt dar, hafif sarımsı orta dorsal şerit, bazen tipik yeşilimsi veya kahverengimsi olduğu görülür. Büyük koyu lekeler vücudun her yerinde dağınık ve ventral taraf beyazımsıdır. Boğaz vücudun geri kalanından daha koyudur. Ayrıca bu tür IUCN listesinde LC kategorisinde listelenmiştir (Öz ve ark. 2009).

Amfibiler yüksek geçirgenlikte bir deri yapısına sahip oldukları için yaşadıkları habitatta meydana gelebilecek değişimlere karşı oldukça hassastırlar, olumsuz değişimler ölümlerine sebep olabilir. Bu nedenle yaşadıkları habitatta meydana gelebilecek antropojenik etkiler, iklim değişimindeki ani olaylar, habitatta predatör varlığının fazlalığı, suyun kimyasal yapısındaki değişimler amfibilerin yaşam koşullarını etkileyebilir (Duellman ve Trueb 1994). Hayat koşullarındaki değişimler amfibiler tarafından kolaylıkla algılanır ve türe özgü korunma davranışları sergilenir. Olumsuz çevre koşullarının yanı sıra dış göçler de, amfibi populasyonunun büyüklüğü üzerinde önemli bir etkiye sahiptir. Sucul habitatta meydana gelebilecek değişimlere karşı oldukça hassas olmaları nedeniyle su rengi, bulanıklık, pH, su sürekliliği, çevredeki bitki örtüsü ve yoğunluğu gibi değişkenler üreme alanı seçimlerini doğrudan veya dolaylı olarak etkileyebilir (Evans ve ark. 1996, Gascon 1991, Spieler ve Linsenmair 1997, Sayım ve ark. 2009, Welsh ve Ollivier 1998, Werner ve Glennemeier 1999). Ekolojik dengede önemli bir yeri olan amfibilerin korunabilmesi için öncelikle habitatlarının korunması gereklidir.

Ülkemiz, coğrafik konumundan dolayı Asya ile Avrupa kıtaları arasında hem doğal bir köprü hem de bariyer konumundadır. Pek çok farklı kökenden fauna elemanının kesişim noktası konumunda olan Türkiye, bünyesinde barındırdığı yaklaşık 160 amfibi ve sürüngen türü ile neredeyse Avrupa kıtası kadar zengin bir potansiyele sahiptir. Ülkemizde belli bölgelerin amfibi türlerinin incelenmesini ele alan pek çok herpetofaunik çalışma yapılmış olmasına rağmen barındırdığı biyolojik çeşitlilik açısından koruma altına alınmış bölgelerdeki hedef türlerin populasyon durumlarını belirten çalışmalar sınırlı düzeydedir. Aslında koruma altına alma çalışmalarına öncelikle üreme habitatları ve yakın çevrelerinin korunması gerekmektedir. Fakat koruma çalışmalarına başlamadan önce, üreme veya kışlama habitatlarında amfibi tür zenginliğinin ortaya konulması 
ve türlerin habitattaki varlığına etki eden ekolojik değişkenlerin bilinmesi gerekmektedir. Hedef bir türe ait populasyon dinamiğinin ve demografik parametrelerinin anlaşılması koruma biyolojisinin temelini oluşturmaktadır. Bu tür bilgileri elde etmek içinse Yakala-Markala-Tekrar Yakala (YM-T) yöntemi biyologlar ve ekologlar tarafından sıkça kullanılan ve populasyonlar hakkında detaylı bilgiler veren en iyi metotlardan biridir. Bu yöntem sayesinde elde edilen veriler üzerinde çalışılan tür ekolojisi hakkında bilgi verilebileceği gibi, populasyondaki ergin bireylerin sayısı, dişi: erkek oranları, yakalanma olasılığı ve hayatta kalma olasılığı hakkında da bilgi verilebilmektedir. (Buckland ve ark. 2000, Burnham ve ark. 1987, Lebreton ve ark. 1992, Pollock ve ark. 1990).

$\mathrm{Bu}$ kapsamda yapılan çalışmada $P$. bedriagae türünün YM-T yöntemi kullanilarak Sakligöl populasyonunun, populasyon büyüklüğünün, yakalanma olasılıklarının ve yıllık hayatta kalma oranlarının hesaplanması amaçlanmıştır.

\section{Materyal ve Metod}

Çalışma alanı: Çalışma, Denizli iline bağlı Honaz ilçesinin Yukarıdağdere Köyü'nde bulunan Saklıgöl göletinde yapılmıştır (yükseklik: 960m). Çevresi sazlıklarla kaplıdır ve yakın çevresinde bulunan çam ormanı ile yakın temas halindedir. Özellikle ilkbahar ve yaz aylarında mesire alanı ve kamp alanı olarak kullanılmaktadır.

Arazi çalışmaları ve yöntem: YM-T yönteminde hayvanlar $30 \mathrm{~cm}$ çapında bir atrap veya elle yakalandiktan sonra markalama işlemlerin tamamlanmasina kadar $25 \times 40 \times 20 \mathrm{~cm}$ ebatlarında plastik taşıma kaplarında saklanmıştır. Yakalanan hayvanlara markalama işleminde bireysel markalama yöntemi uygulanmış ve mümkün olduğunca minimum düzeyde görmesi sağlanmıştır. Markalama işlemi dijital fotoğraf makinesi ile gerçekleşmiştir. Fotoğraf çekiminde Nikon D5000 dijital fotoğraf makinesi kullanılmış olup, yakalanıp fotoğrafı çekilen tüm hayvanlara birer kod verilmiş ve bu kodun yanı sıra cinsiyet, yakalanma tarihi de not edilmiştir. $P$. bedriagae türünün dorsal tarafındaki desenlerin markalama işlemi için uygun olduğuna karar verilmiş ve bireysel olarak tanıma işlemi bu bölgelerden gerçekleşmiştir (Başkale ve Kaya 2012). Arazi çalışmasında yakalanan bireyler plastik saklama kabında tutulurken fotoğraf çekimleri özel olarak bulunan cam fanus içinde ve hayvanlara $15 \mathrm{~cm}$ uzaklıktan yapılmıştır. Fotoğraf çekiminden sonra hayvanlar bırakılmış ve veriler bilgisayara transfer edilmiştir. Fotoğraflar, arazi tarihine ve bireylerin cinsiyet verileri göz önüne alınarak farklı klasörler içinde depolanmıştır. Daha sonra hedef lokalitedeki farklı arazi dönemlerine ait fotoğraflar Microsoft Office Picture manager programı yardımıyla görsel olarak karşılaştırılmış ve farklı klasörlerdeki aynı bireye ait fotoğraf kodları kaydedilmiştir. Elde edilen veri seti, Program Mark (Cooch ve White 2004, White ve Burnham 1999) ile analiz edilmiştir. Elde edilen sonuçlar Program Capture (Otis ve ark. 1978) ile test edilmiştir.

YM-T yöntemi uygulanmasında, markalama işleminin dijital fotoğraf makinesi ile gerçekleştiğinden, markalama işleminin doğru bir şekilde yapıldığı ve markaların sürekli olduğu ve farklı örneklem dönemlerinde ayırt edilebildiği, markalanmış ve markalanmamış bireylerin eşit yakalanma olasılıklarına, eşit ölme veya dış göç yapma şansına sahip olduğu varsayılmıştır. Bu varsayımları test etmek için tekrar yakalanma olasıliklarda meydana gelebilecek varyasyonlar incelenmiş ve ilk kez Pollock (1974) tarafından tanımlanan ve Otis ve ark. (1978)'nın CAPTURE bilgisayar programı ile birlikte hazırladığı bir kılavuzda ayrıntılı bir şekilde ele alınan modeller değerlendirilmiştir. $\mathrm{Bu}$ modeller, temelde 3 faktörden meydana gelmektedir. Bu faktörler, tekrar yakalanma olasiliklarda meydana gelebilecek zamansal (t), davranışsal (b) ve heterojeniteden (h) kaynaklanan varyasyonlardır. Bu üç faktörün varlığına ve yokluğuna göre $M(o), M(h), M(b), M(b h), M(t), M(t h), M(t b)$ ve $\mathrm{M}(\mathrm{tbh})$ şeklinde gösterilen, toplam sekiz değişik kapalı populasyon modelden oluşmaktadır.

\section{Sonuçlar}

Pelophylax bedriagae türünün populasyon büyüklügünü incelemek için Saklıgöl'de ilkbahar ve yaz dönemlerini kapsayacak şekilde 4 defa arazi çalışması gerçekleştirilmiştir. Örneklem tarihleri ve yakalanan birey sayılarına ait veriler Tablo 1'de verilmiştir. Bu çerçevede toplam 141 birey yakalanmış ve her biri markalanmıştır. Populasyonun erkek-dişi oranının 1:1,3 dişi eğilimli populasyon olduğu ortaya çıkmıştır.

Tablo 1: Saklıgölde uygulanan YM-T yöntemine ait veriler

\begin{tabular}{|c|c|c|c|c|c|c|}
\hline $\begin{array}{l}\text { Örneklem } \\
\text { No }\end{array}$ & $j=$ & 1 & 2 & 3 & 4 & \\
\hline $\begin{array}{l}\text { Örneklem } \\
\text { Tarihi }\end{array}$ & & $\begin{array}{l}18.05 . \\
2015\end{array}$ & $\begin{array}{l}03.07 . \\
2015\end{array}$ & $\begin{array}{l}25.07 . \\
2015\end{array}$ & $\begin{array}{l}15.08 . \\
2015\end{array}$ & Toplam \\
\hline $\begin{array}{l}\text { Yakalanan } \\
\text { birey sayısı }\end{array}$ & $n(j)=$ & 35 & 36 & 26 & 44 & 141 \\
\hline $\begin{array}{l}\text { Toplam } \\
\text { yakalanma }\end{array}$ & $M(j)=$ & 0 & 35 & 67 & 92 & 128 \\
\hline
\end{tabular}

Saklıgöl populasyonu bu sekiz kapalı populasyon modeli olarak değerlendirilmiş ve $\mathrm{M}(\mathrm{o})$ modelinin en uygun model olduğu tespit edilmiştir (Tablo 2). Bu model, tüm bireylerin, her bir örnekleme evresinde eşit yakalanma olasılığına sahip olduğunu göstermektedir. Yani, yakalama ve markalama işlemleri esnasında bireylerin davranış değişikliğine ve yaralanmasına neden olacak hiçbir işlem yapılmamıştır. Populasyon büyüklüğü hesaplamaları sonucunda $P$. bedriagae türünün populasyon büyüklüğü 544 \pm 134.3 (\% 95’lik Güven Aralığ $\left.\breve{1}_{1}=353-899\right)$ birey olarak hesaplanmıştır. Türün arazi çalışmaları döneminde yakalanma olasılıkları $p(t)$ ve Hayatta kalma oranları $\phi(t)$ Tablo 3 'te verilmiştir. Program MARK altındaki açık populasyon modeli olan Joly-Seber metodunun $\phi(t) \quad p(t)$ modeline göre hesaplanmıştır. $\mathrm{Bu}$ modelde populasyon açık olarak kabul edildiğinden arazi çalışmaları arasında geçen süre içerisinde populasyona yeni katılımların olduğu ve bazı bireylerin diş göç yapabileceği ya da ölebileceği varsayılmıştır. Buna göre yıllık ortalama yakalanma olasılığ1 0.62 iken hayatta kalma oranı 0.32 olarak hesaplanmıştır.

Tablo 2: Kapalı populasyon modellerine ait değerlendirmeler

$\begin{array}{lllllllll}\text { Model } & \begin{array}{l}\mathrm{M} \\ (\mathrm{o})\end{array} & \begin{array}{l}\mathrm{M} \\ (\mathrm{h})\end{array} & \begin{array}{l}\mathrm{M} \\ (\mathrm{b})\end{array} & \begin{array}{l}\mathrm{M} \\ (\mathrm{bh})\end{array} & \begin{array}{l}\mathrm{M} \\ (\mathrm{t})\end{array} & \begin{array}{l}\mathrm{M} \\ (\mathrm{th})\end{array} & \begin{array}{l}\mathrm{M} \\ (\mathrm{tb})\end{array} & \begin{array}{l}\mathrm{M} \\ (\mathrm{tbh})\end{array} \\ \text { Kriter } & 1,00 & 0,71 & 0,12 & 0,48 & 0,00 & 0,13 & 0,22 & 0,59\end{array}$


Tablo 3: $P$. bedriagae türünün yakalanma olasılıkları, hayatta kalma oranları ve \%95'lik Güven aralıkları

\begin{tabular}{|c|c|c|c|c|}
\hline Parametre & Tarihler & Tahmin & $\begin{array}{l}\text { Standart } \\
\text { Hata }\end{array}$ & $\begin{array}{l}\text { (\% 95'lik Güven } \\
\text { Aralığı) }\end{array}$ \\
\hline \multirow{3}{*}{ 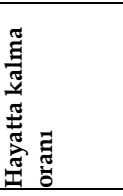 } & $\begin{array}{l}\text { 18.05.2015- } \\
\text { 03.07.2015 }\end{array}$ & 0,20 & 0,002 & $0,203651-0,203657$ \\
\hline & $\begin{array}{l}\text { 03.07.2015- } \\
25.07 .2015\end{array}$ & 0,12 & 0,002 & 0,116953-0,11696 \\
\hline & $\begin{array}{l}25.07 .2015- \\
15.08 .2015 \\
\end{array}$ & 0,63 & 0,002 & $0,632241-0,632251$ \\
\hline \multirow{4}{*}{ 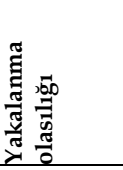 } & 18.05 .2015 & 0,95 & 0,001 & $0,952537-0,952542$ \\
\hline & 03.07.2015 & 0,71 & 0,003 & 0,709132-0,709143 \\
\hline & 25.07.2015 & 0,37 & 0,002 & $0,374335-0,374343$ \\
\hline & 15.08.2015 & 0,44 & 0,001 & $0,441175-0,441179$ \\
\hline
\end{tabular}

\section{Tartışma}

Amfibi populasyonlarının azalması yada yok olması hakkında ilk kez 1989 yılında Birinci Dünya Herpetoloji kongresinde bahsedilmiş ve son 30 yll içerisinde bu fenomen, küresel bir problem haline gelmiştir. (Alford ve Richards 1999, Barinaga 1990, Beebee ve Griffiths 2005, Blaustein ve Wake 1990, Gardner 2001, Houlahan ve ark. 2001, La Marca ve ark. 2005, Ron ve ark. 2003, Stuart ve ark. 2004, Wake 1991, Wyman 1990). Dünyadaki amfibi biyoçeşitliliğindeki azalmalar son zamanlarda iyi bir şekilde rapor edilmesine rağmen, bazı türlerin populasyon durumları hakkında hala yeterli bilgiler mevcut değildir. Hâlbuki hedef bir türe ait populasyon dinamiğinin ve demografik parametrelerinin anlaşılması koruma biyolojisinin temelini oluşturmaktadır (Marsh ve Trenham 2001). Bu tip bilgileri elde etmek için ise YM-T yöntemi biyologlar ve ekologlar tarafından kullanılan iyi bir araçtır (Donnelly ve Guyer 1994, Lebreton ve ark. 1992).

Ülkemizde amfibilerin populasyon büyüklüğü ile ilgili çalışmalar oldukça az sayıda olup, giderek artmaktadir (Ayaz ve ark. 2007, Baran ve ark. 2001, Başkale ve Kaya, 2012, Çapar ve Başkale 2016, İsmail ve Çiçek 2017, Kaya ve ark. 2005, Kaya ve Erişmiş 2001, Mermer ve ark. 2008, Yıldız ve Göçmen 2012). Ülkemizde yapılan amfibilerin populasyon büyüklüğü ile ilgili ilk çalışma Rana holtzi türü üzerine gerçekleştirilmiş, türün tip lokalitesi olan Karagöl'de (Ulukışla-Niğde) göl kenarının her $\mathrm{m}^{2}$ sinde yaklaşık olarak 7-11 ergin bireyin bulunduğu ve bu değerlerden hareketle gölde yaklaşık 30 bin kurbağadan oluşan bir populasyonun bulunduğu ileri sürülmüştür (Baran ve ark. 2001). Yine aynı kaynağa göre, göle aşılanan aynalı sazan (Cyprinus carpio) populasyonu gölün biyolojik dengesini bozduğu ve bunun sonucu olarak $R$. holtzi populasyonunun daha önceki yıllara göre \% 60-70 oranında azaldığı ileri sürülmüştür. Kaya ve ark. (2005), devam niteliğinde yaptıkları çalışmada, $R$. holtzi türünün Karagöl populasyon büyüklüğünü ortalama 1059 olarak hesaplanmışlardır. Aynı şekilde Karagöl'de 2009 yılında arazi çalışmaları gerçekleştirilmiş ve 2003 verileri, 2009 verileri ile karşılaştırılarak hem hesaplama yöntemleri arasındaki farklar hem de populasyon büyüklüğündeki ciddi azalma $(1999=\sim 30.000$ birey; $2003=14.741$ birey; $2009=3.125$ birey) göz önüne serilmiştir (Kaya ve ark 2010). Benzer çalışmalar, farklı türlerin farklı habitatlarında incelenmiştir. Örneğin, $R$. ridibunda türünün populasyon büyüklüğü hesaplamaları Afyon, Akören Gölü'nde (Kaya ve Erişmiş 2001) ve Denizli, Yayla Gölünde (Ayaz ve ark. 2007) gerçekleştirilmiştir.
Mermer ve ark. (2008) tarafından gerçekleştirilen çalışmada, T. karelinii ve T. vittatus türlerinin Uludağ populasyonlarına ait populayon büyüklükleri ortaya çıarılmıştır. Bunları takiben Kaya ve Başkale (2012), Pelophylax bedriagae türünün İzmir, Karagöl populasyon büyüklüğünü 2006, 2007, 2008 ve 2009 yılları için sırasıyla $245,301,67$ ve 54 birey olarak hesaplamış ve ciddi bir azalma olduğunu ileri sürmüştür. Yine aynı çalışmada Soğanharımı göletinin (Bornova-İzmir) tamamen tahrip edildiğini rapor etmiştir. Çiçek ve ark. (2011) Rana macrocnemis türünün Uludağ (Bursa) populasyonlarının büyüklükleri hakkında değerli bilgiler vermiştir. Bu çalışmada, Honaz ilçesinin Yukarıdağdere Köyü'nde bulunan Saklıgöl'de $P$. bedriagae türünün populasyon büyüklüğü 544 birey olarak hesaplanmıştır. Yapılan bu çalışma tek yıllık verileri içerdiğinden populasyon büyüklüğündeki dalgalanmaları içermemektedir. Ancak, yakalama olasılıkları türün yaklaşık olarak \% 62'sinin örneklendiğini göstermektedir. Hayatta kalma oranı ise üreme dönemlerinde ortalama 0,32 olarak hesaplanırken bu değer 0,12-0,63 arasında değişmektedir. Bu değerler doğal populasyonlar için ideal değerlerdir. Örneğin Rana temporaria için bu değerler 0,25-0,50 arasında (Beebee ve Griffiths 2000), Rana macrocnemis için çeşitli populasyonlarda 0,57-0,94 arasında (Çiçek ve ark. 2011) Hyla arborea için ortalama 0,297 (Pellet ve ark. 2007), Ommatotriton ophryticus için ortalama 0,35 (Başkale ve ark. 2013) ve $P$. bedriagae türünün Karagöl populasyonu için yıllık ortalama 0,301 olarak (Başkale ve Kaya 2012) hesaplanmıştır.

Sonuç olarak, $P$. bedriagae türünün Saklıgöl populasyonun 2015 üreme dönemi için populasyon büyüklüğü 544 birey olarak hesaplanmıştır. Bu değer daha sonraki yıllarda yapılacak çalışmalar için bir referans değeri niteliğinde olup populasyondaki azalma ve artışlar, habitatın maruz kaldığı tehlikeler için bir gösterge olacaktır.

\section{Kaynaklar}

Alford, R. A., Richards, S. J. 1999: Global amphibian declines: a problem in applied ecology. Annual Reviews of Ecology and Systematics, 30: 133165.

AmphibiaWeb, 2017: http://amphibiaweb.org/, erişim tarihi 20.11.2017

Ayaz, D., Tok, C. V., Mermer, A., Tosunoğlu, M., Afsar, M., Çiçek, K. 2007: Population size of the marsh frog (Rana ridibunda Pallas, 1771) in Lake Yayla (Denizli, Turkey). Turkish Journal of Zoology, 31: 255-260.

Baran, İ., Balık, S., Kumlutaş, Y., Tok, C. V., Olgun, K., Durmuş, H., Türkozan, O., Ilgaz, Ç., İret, F. 2001: Rana holtzi (Toros Kurbağası)'nin Biyolojik ve Ekolojik Yönden Araştırılması ve Koruma Stratejisinin Saptanmasi. $4^{\text {th }}$ Ulusal Ekoloji ve Çevre Kongresi, Bodrum, Turkey, 213-218.

Baran, İ., Atatür, M. K. 1998: Turkish Herpetofauna (Amphibians and Reptiles), T.C. Çevre Bakanlığı, Ankara

Barinaga, M. 1990: Where have all the froggies gone? Science, 247: 10331034.

Başkale E., Kaya, U. 2012: Decline of Levantine Frog Pelophylax bedriagae Camerano, 1882 in the western Aegean Region of Turkey: Changes in Population size and implication for conservation. Zoology in the Middle East, 57: 69-76.

Başkale, E., Yıldırım, E., Çevik, İ. E., Kaya, U. 2013: Population size and age structure of metamorphic and pedomorphic forms of Ommatotriton ophryticus (Berthold, 1846) in Northwestern Black Sea Region of Turkey. Journal of Herpetology, 47: 270-276. 
Beebee, T. J. C., Griffiths, R. A. 2005: The amphibian decline crisis: A watershed for conservation biology? Biological Conservation, 25: 271285

Blaustein, A. R., Wake, D. B. 1990: Declining amphibian populations: a global phenomenon. Trends in Ecology and Evolution, 5: 203-204.

Buckland, S. T., Goudie, I. B. J., Borchers, D. L. 2000: Wildlife population assessment: Past developments and future directions. Biometrics, 56: $1-12$.

Budak, A., Göçmen, B. 2005: Herpetoloji, Ege Üniversitesi Fen Fakültesi Yayınları, No : 194, Bornova, İzmir.

Burnham, K. P., Anderson, D. R., White, G. C., Brownie, C., Pollock., K. H. 1987: Design and analysis methods for fish survival experiments based on release-recapture, No: 5, Maryland. USA American Fisheries Society Monograph Bethesda, 437.

Cooch, E., White, G. C. 2004: Program MARK A Gentle Introduction. 5th Ed. Available from: http://www.phidot.org/software/mark/docs/book/, 545 pp.

Çapar, D., Başkale, E. 2016: Population size of endemic Rana tavasensis in its terra typica, Turkey. Turkish Journal Zoology, 40: 729-733.

Çiçek, K., Mermer, A., Tok, C. V. 2011: Population dynamics of Rana macrocnemis Boulenger, 1885 at Uludağ, Western Turkey. Zoology in the Middle East, 53: 41-60

Donnelly, M. A., Guyer, C. 1994: Mark-recapture. In: Heyer, W. R. Donnelly, M. A., McDiarmid, R. W., Hayek, L.C., Foster, M.S., (Eds), Measuring and Monitoring Biological Diversity: Standard methods for Amphibians. Smithsonian Institution Press. Washington D.C., pp. 183 200

Duellman, W. E., Trueb, L. 1994: Biology of Amphibians, London. The John Hopkins Press Ltd.

Evans, M., Yaber, C., Hero, J. M. 1996: Factors influencing choice of breeding site by Bufo marinus in its natural habitat. Copeia, 904-912.

Gardner, T. 2001: Declining amphibian populations: a global phenomenon in conservation biology. Animal Biodiversity and Conservation, 24 (2): $25-44$

Gascon, C. 1991: Population- and community-level analyses of species occurrences of central amazonian rainforest tadpoles. Ecology, 72: $1731-46$

Houlahan, J. E., Findlay, C. S., Schmidt, B. R., Meyer, A. H., Kuzmin, S. L. 2001: Quantitative evidence for global amphibian population declines. Nature, 404: 752-755.

İsmail, İ. B., Çiçek, K. (2017): Population size, Age Structure and Life cycle of Levant water frog, Pelophylax bedriagae (Camerano, 1882) (Amphibia: Anura: Ranidae) in Lake Sülüklü (Manisa). Ege Journal of Fisheries and Aquatic Sciences, 34(2): 169-177. doi:10.12714/egejfas.2017.34.2.08

IUCN, The IUCN Red list of threatened species, 2017: www.iucnredlist.org, 19.11.2017

Kaya, U., Erişmiş, U. C. 2001: Marsh frogs, Rana ridibunda in Lake Akören 26 August National Park (Afyon): A preliminary study of population size and a taxonomical evaluation. Turkish Journal of Zoology, 25: 3134 .

Kaya, U., Çevik, İ. E., Erişmiş, U. C. 2005: Population status of the Taurus frog Rana holtzi Werner (1898), in its terra typica: Is there a decline? Turkish Journal of Zoology, 29: 317-319.

Kaya, U., Başkale, E., Çevik, İ. E., Kumlutaş, Y., Olgun, K. 2010: Population sizes of taurus frog, Rana holtzi, in two different localities, Karagöl and Eğrigöl: new estimations, decline, and awarning for their conservation. Russian Journal of Herpetology, 17(4): 247-250.

La Marca, E. Lips, K. R., Lötters, S., Puschendorf, R., Ibáñez, R. 2005: Catastrophic population declines and extinctions in Neotropical harlequin frogs (Bufonidae: Atelopus). Biotropica, 37: 190-201.

Lebreton, J. D., Burnham, K. P., Clobert, J., Anderson, D. R. 1992: Modeling survival and testing biological hypotheses using marked animals: A unified approach with case studies. Ecological Monographs, 62: 1-118.

Marsh, D. M., Trenham, P. C. 2001: Metapopulation dynamics and amphibian conservation. Conservation Biology, 15: 40-49.
Mermer, A., Ayaz, D. ve Çiçek, K. 2008: Abundance of Syntopic Newts, Triturus karelinii (Strauch, 1870) and Triturus vittatus (Gray, 1835), in Uludağ National Park (Bursa, Turkey). Turkish Journal of Zoology, 32: 59-64.

Otis, D. L. Burnham, K. P, White, G. C., Anderson, D. R. 1978: Statistical inference from capture data on closed animal populations. Wildlife Monographs, 62.

Öz, M., Kaska, Y., Kumlutas, Y., Kaya, U., Avci, A., Üzüm, N., Yeniyurt, C., Akarsu, F., Kasparek, M. 2009. Pelophylax caralitanus. The IUCN Red List of Threatened Species 2009: e.T135806A4203649. http://dx.doi.org/10.2305/IUCN.UK.2009.RLTS.

T135806A4203649.en. Downloaded on 23 December 2017.

Pellet, J., Helfer, V., Yannic, G. 2007: Estimating population size in the European tree frog (Hyla arborea) using individual recognition and chorus counts. Amphibia-Reptilia, 28: 287-294.

Pollock, K. H. 1974: The assumption of equal catchability of animals in tag-recapture experiments. Ph.D. Thesis, Cornell University, Ithaca, NY.

Pollock, K. H., Nichols, J. D., Brownie, C., Hines, J. E. 1990: Statistical Inference for Capture-Recapture Experiments. Wildlife Monograpgh, 107: 1-97.

Ron, S. R., Duellman, W. E Coloma, L. A Bustamante, M. R. 2003 Population Decline of the Jambato Toad Atelopus ignescens (Anura: Bufonidae) in the Andes of Ecuador. Journal of Herpetology, 37(1): 116-126.

Sarıkaya, B., Yıldız, M. Z., Sezen, G. 2017: The Herpetofauna of Adana Province (Turkey). Commagene Journal of Biology, 1: 1-11.

Sayım, F., Başkale, E., Tarkhnishvili, D., Kaya, U. 2009: Some water chemistry parameters of breeding habitats of the Caucasian salamander, Mertensiella caucasica in the Western Lesser Caucasus. Comptes Rendus Biologies, 332: 464-69.

Spieler, M., Linsenmair, K. E. 1997: Choice of optimal oviposition sites by Hoplobatrachus occipitalis (Anura: Ranidae) in an unpredictable and patchy environment. Oecologia, 109: 184-99.

Stuart, S., Chanson, J. S., Cox, N. A., Young, B. E., Rodrigues, A. S. L., Fishman, D. L., Waller, R. W. 2004: Status and trends of amphibian declines and extinctions worldwide. Science, 306: 1783-1786.

Wake, D. 1991: Declining Amphibian Populations. Science, 253: 860.

Welsh, H. H., Ollivier, L. M. 1998: Stream amphibians as indicators of ecosystem stress: a case study from California's redwoods. Ecological Applications, 8(4): 1118-32.

Werner, E. E., Glennemeier, K. S. 1999: Influence of forest canopy cover on the breeding pond distributions of several amphibian species. Copeia, 1999: 1-12.

White, G. C., Burnham, K.P. 1999: Program MARK: Survival estimation from populations of marked animals. Bird Study, 46:120-138.

Wyman, R. L. 1990: What's happening to the amphibians? Conservation Biology, 4: 350-352.

Yıldız, M. Z., Göçmen, B. 2012: Population dynamics, reproduction, and life history traits of Taurus Frog, Rana holtzi Werner, 1898 (Anura: Ranidae) in Karagöl (Ulukışla, Niğde), Turkey. Herpetologica Romanica, 6: 1-40. 